\title{
Thesaurus da educação popular e da educação de jovens e adultos
}

\author{
MARIA MARGARIDA MACHADO \\ Universidade Federal de Goiás, Goiânia, GO, Brasil
}

FÁvero, Osmar; Motta, Elisa (Orgs.). Educação popular e educação de jovens e adultos. 1. ed. Petrópolis: De Petrus et Alli; Rio de Janeiro: FAPERJ, 2015. DVD-Rom.

Chamamos assim os três DVDs organizados por Osmar Fávero e Elisa Motta, uma produção do Núcleo de Estudos e Documentação em Educação de Jovens e Adultos (NEDEJA) da Universidade Federal Fluminense (UFF), disponibilizada em 2015 pela editora De Petrus et Alli em formato eletrônico. Reúne o acervo resultante de pesquisa documental e bibliográfica, abarcando as temáticas da educação popular e da educação de jovens e adultos, do contexto da década de 1940 aos dias atuais.

É um verdadeiro tesouro para a história da educação popular e da educação de jovens e adultos do Brasil, pela riqueza do acervo digitalizado e pelo potencial em pesquisa que se abre para esses campos, com base no acesso a mais de duas mil fontes, que seguem sendo atualizadas pela equipe do NEDEJA. Como é dito no folheto de apresentação dos DVDs, no conjunto documental encontram-se projetos, programas, propostas e documentos instituidores de campanhas e movimentos, relatos de experiência, depoimentos, entrevistas, livros, artigos, fotos, depoimentos e entrevistas, números especiais de periódicos sobre a temática, especialmente material didático, entendido em sentido amplo: cartilhas, livros, cordel, vídeos, filmes, fotos, diapositivos etc.

Resenhar essa riquíssima produção requer enfrentar dois desafios: o primeiro, e mais fácil de superar, é dar aos leitores a exata noção de como se produziu essa publicação e como está disponível para acesso, porque se trata de um belíssimo conjunto eletrônico, acompanhado de um folheto explicativo do processo de organização dos documentos. O segundo, que não ouso dizer que será superado, é apresentar o que compõe o thesaurus, nessa publicação de 2015, em seu conteúdo e valor afetivo, histórico e político.

\section{NOVA FORMA PARA DAR ACESSO A UM CONTEÚDO QUASE INVISÍVEL}

Como os próprios organizadores do material reconhecem, retirar a educação popular e a educação de jovens e adultos da invisibilidade em que se encontram na 
história da educação brasileira é um dos grandes méritos dos DVDs produzidos pelo NEDEJA. O meio possível para que isso ocorresse, em plena era digital, no século XXI, foi com a virtualização do material acessado na pesquisa documental.

Estamos falando de um tratamento documental digitalizado de 1.157 documentos, correspondendo a 59.164 páginas, ocupando o espaço de vinte gigabytes. Mas isso não é suficiente para expressar o que de fato significa o trabalho de uma pesquisa que envolve localizar fontes documentais, tratar a documentação encontrada, o que implica higienização, restauração e catalogação e posterior digitalização para disponibilizar aos leitores. Envolve também ouvir os sujeitos históricos que viveram e vivem as experiências apresentadas; convencê-los de que é necessário falar sobre o vivido, por mais que para alguns isso represente reabrir feridas ou reviver utopias; garimpar os vestígios dessas histórias com esses sujeitos, alguns dos quais, importante comentar, sobreviveram ao golpe militar de 1964, ou aos inúmeros "golpes" que sofreram e sofrem os movimentos populares e as instituições públicas, com mudanças de dirigentes que impactam as descontinuidades das ações em educação.

A referida pesquisa reúne um conjunto de diferentes materiais nunca antes disponibilizado. Há peças raras, originais e únicas; há documentos oficias e produções quase artesanais que registram experiências de processos educativos vivenciados no âmbito de ações e programas de governo, bem como realizadas por entidades e movimentos da sociedade civil, envolvidos com a temática da educação popular e a educação de jovens e adultos. Não houve intenção, por parte dos organizadores do thesaurus, de produzir análises ou interpretações com o documentado; são apresentadas fontes primárias, matéria-prima para estudos e pesquisas, ou para ser explorada em aulas e seminários. O NEDEJA apenas situou, historicamente, no tempo e no espaço, os documentos relativos às experiências e aos movimentos e, quando possível, remeteu ou reproduziu o que foi feito sobre eles na forma de depoimentos, livros, artigos, relatórios, dissertações e teses.

A organização do material de pesquisa nessa publicação de 2015 resultou em três DVDs assim denominados: "Educação popular I"; "Educação popular II"; e "Educação de jovens e adultos". Uma primeira versão do DVD-Rom "Educação popular I" foi divulgada em 2004, ampliada em 2013, e encontra-se inteiramente disponibilizada no portal: www.forumeja.org.br/edupopular. Espera-se que o mesmo possa ocorrer com o restante do material disponível nos outros dois DVDs, o que facilitará ainda mais o acesso dos demais pesquisadores ao rico conteúdo dessa pesquisa documental, que passamos a apresentar a seguir.

\section{EDUCAÇÃO POPULAR I (1947/1967) OU “UM IMPULSO DE CAMPANHAS E MOVIMENTOS NA EDUCAÇÃO DE ADULTOS”}

Esse conjunto de documentos reúne ações de governo e da sociedade civil em prol da alfabetização de adultos. Começa com a apresentação do material governamental relativo às campanhas de alfabetização e educação rural de 1947 a 1955, implementadas pelo então Ministério da Educação e Saúde Pública e os designados movimentos de cultura popular e educação popular do início da década de 1960: 
Movimento Popular de Cultura (MCP), inicialmente do Recife e depois ampliado para o estado de Pernambuco; Movimento de Educação de Base (MEB), convênio entre a Igreja católica e o governo federal; Centro de Cultura Popular (CPC) da União Nacional dos Estudantes (UNE); Campanha "De pé no chão também se aprende a ler", iniciativa do município de Natal, Rio Grande do Norte; Campanha de Educação Popular da Paraíba (CEPLAR); Sistema de Educação de Adultos Paulo Freire, principalmente a experiência de Angicos, em 1963, e a proposta do Plano Nacional de Alfabetização, implantado pelo Governo João Goulart e abortado pelo golpe militar em 1964.

\section{EDUCAÇÃO POPULAR II (1972/...) OU “REENCONTRO COM UTOPIAS E NOVOS ATORES NO CENÁRIO DA EDUCAÇÃO DOS TRABALHADORES”}

Esse DVD abarca um total de 328 documentos, produzidos por dez organizações da sociedade civil, constituídas durante e após o regime militar no Brasil, com forte presença de lideranças católica e protestante, afiliadas à concepção da teologia da libertação, bem como com a resistência de militantes sindicais e partidários, defendendo uma concepção emancipatória de educação influenciada principalmente pelo pensamento marxista e maoista. Vamos conhecer um pouco sobre cada uma dessas organizações.

O Centro de Trabalho e Cultura (CTC) foi uma escola de trabalhadores voltada à profissionalização de jovens e adultos da Região Metropolitana do Recife, que nasceu da experiência do MEB/Recife em 1963. Filiava-se ao Conselho de Escolas de Trabalhadores (CET), que reunia um coletivo de escolas criadas por operários ainda no contexto da ditadura militar, em oposição à política de educação profissional desse regime, questionando principalmente a formação de trabalhadores implementada pelo Sistema S, em especial o Serviço Nacional de Aprendizagem Industrial (SENAI). Esse coletivo de escolas, o CET, chegou a reunir, no final da década de 1970, cerca de doze dessas iniciativas de escolas operárias, que funcionavam nas cidades de São Paulo, Rio de Janeiro, Belo Horizonte, Salvador e Recife, com trabalhadores sobretudo da indústria e da metalurgia. Manteve uma sistemática de seminários anuais até o ano de 1985, sobrevivendo às políticas neoliberais dos anos de 1990. Com o final dos financiamentos internacionais e as mudanças nas relações sociopolíticas internas, com exceção do CTC, essas escolas encerraram suas atividades em meados dos anos 2000.

O MEB, já apresentado no DVD I, no contexto pós-década de 1970 é retomado em seus esforços de renovação dos sistemas radioeducativos, que permaneceram funcionando após o golpe de 1964. Essa resistência e renovação de práticas fazem o MEB chegar aos anos 2000 primeiramente atuando na região do Vale do Jequitinhonha (Minas Gerais), para em seguida resgatar sua atuação no Maranhão, Piauí, Ceará, Roraima e Distrito Federal e, principalmente, expandindo-a na Amazônia. 
O Centro Ecumênico de Documentação e Informação (CEDI) nasceu do Centro Evangélico de Informação (CEI). Inicialmente contando com militantes ligados a Confederação Evangélica do Brasil, entre os anos de 1964 e 1965 passa a incorporar militantes católicos, configurando-se em um grupo ecumênico de assessoria e publicações que versavam sobre a conjuntura brasileira do período da ditadura militar e o processo de reabertura política. Até 1994 atuou articulada a organismos nacionais, latino-americanos e mundiais, tendo então se desdobrado em quatro outras instituições: Instituto Socioambiental; Núcleo de Estudos, Trabalho e Sociedade; Koinonia; e Ação Educativa. Esta última assumiu o acervo e a tradição de produção de material didático-pedagógico voltado para a educação de jovens e adultos. Herdou ainda do CEDI a prática de assessoria a movimentos e grupos organizados em torno da pauta da educação, estendendo-se para a formação de professores das redes públicas de ensino e para a produção de referenciais e livros didáticos com financiamento do governo federal, desde meados da década de 1990. Mantém uma rede de relações nacionais e internacionais, com organismos governamentais e não governamentais, que financiam a produção e a divulgação do conjunto de pesquisas que realiza, e não apenas no campo da educação de jovens e adultos, mas nas temáticas mais gerais que abarcam o tripé: educação, juventude e cultura.

O NOVA - Pesquisa, Avaliação e Assessoria foi um grupo de assessoria constituído, a partir de 1972, por profissionais ligados às experiências de mobilização popular, realizadas pelas igrejas católicas e protestantes. Seu funcionamento contou com financiamento decisivo de organismos internacionais até meados de 1990 e, depois, com convênios com prefeituras e empresas para a formação de profissionais para atuarem na área da educação e cultura. Alguns de seus membros se desligaram e criaram dois outros grupos assessores: Serviços de Apoio à Pesquisa em Educação (SAPE) e Cooperação e Apoio a Projetos de Inspiração Alternativa (CAPINA).

O Instituto de Planejamento Regional e Urbano (URPLAN), ligado a Pontifícia Universidade Católica de São Paulo (PUC-SP), entra nesse DVD por ser uma experiência rica de intelectuais professores universitários e outros vindos dos movimentos da Ação Católica, com o objetivo de realizar pesquisas voltadas para a problemática das políticas públicas e assessorar movimentos populares.

O Centro de Educação Popular do Instituto Sedes Sapientiae (CEPIS) foi criado em 1977, no bojo da reestruturação do instituto, este vinculado às cônegas de Santo Agostinho. Sua atuação ficou conhecida como assessoria militante com movimentos populares que buscavam organizar, no contexto de governos autoritários, o atendimento aos interesses das classes operárias.

Os outros centros de educação popular criados no mesmo período também se valeram do apoio de agências internacionais da Europa e do Canadá. Os vários desafios do contexto brasileiro e internacional, inclusive de financiamento, vividos entre as décadas de 1980 e 2000, fizeram com que o CEPIS assumisse pautas diferenciadas nas atividades de assessoria e formação, voltando-se para temas urbanos e rurais, criando o Projeto Formação Básica Multiplicadora.

O Centro de Estudos em Éducação (VEREDA), criado em 1982 por educadores que se somavam a Paulo Freire na defesa da educação popular, iniciou com ações de alfabetização de jovens e adultos, partindo mais tarde para o trabalho com 
mulheres e outras práticas sociais. Sua atuação, após o processo de democratização, vai concentrar-se em assessorias de formação de educadores para movimentos sociais e secretarias de educação.

O Movimento dos Trabalhadores Rurais Sem Terra (MST), criado em 1984, dedica-se à educação de crianças, jovens e adultos, no contexto de sua luta central pelo direito à terra. $\mathrm{Na}$ década de 1990, iniciou sua atuação em convênios com instituições de educação superior na criação de cursos de formação de professores no nível de magistério. Ao fim dessa mesma década, participou do debate com o governo federal na garantia da criação de cursos superiores voltados para a preparação de professores do campo, conhecidos como pedagogia da terra. Trata-se de um movimento que ampliou sua concepção de alfabetização e do direito à educação em todos os níveis, etapas e modalidades, atuando direta ou indiretamente na oferta da educação à população do campo. As escolas itinerantes que acompanham a luta pela terra em acampamentos e assentamentos funcionam com a dedicação dos militantes do movimento e com parcerias com instituições públicas no âmbito local e nacional.

O SAPE foi criado entre os anos de 1983 e 1984 por educadoras que atuaram no MEB e no NOVA com outros educadores que tinham por objetivo dedicar-se à pesquisa no campo da educação popular e da formação política, para contribuir com a formação de educadores de jovens e adultos. Das pesquisas realizadas resultou a publicação do Almanaque do Aluá, um dos materiais didáticos mais inovadores da época, por se tratar de uma variedade de gêneros textuais e temáticas abordadas de forma interdisciplinar, e a constituição do Coletivos de Formação, que representaram uma experiência de trocas e aprofundamentos entre educadores, consolidando instrumentos interessantes de intervenção no seu processo formativo.

A Central Única dos Trabalhadores (CUT) é uma organização de base sindical, criada em 1983, que desde a sua origem investe na formação de seus quadros dirigentes, ou seja, os representantes dos sindicatos que são filiados à central. Inicialmente contava com parceria de várias organizações, também identificadas nesse DVD, que tinham como foco a formação dos trabalhadores. A partir de meados dos anos de 1990, vai dar início a uma ação mais direta na educação profissional, valendo-se da organização de programas de formação de trabalhadores, com recursos do Plano Nacional de Formação Profissional (PLANFOR), operado pelo Ministério do Trabalho e Emprego com recursos do Fundo de Amparo ao Trabalhador (FAT). Nessa experiência passou a definir o Programa Político Pedagógico de Educação e Formação Profissional para Trabalhadores. As duas principais referências dessa atuação da CUT são os programas Integrar e Integração, com um conjunto significativo de materiais produzidos na área da educação profissional, disponibilizados também no DVD.

Como pode ser observado na descrição anterior, o Brasil produziu e segue mantendo um rico mosaico de instituições, constituindo-se em um misto entre movimentos e grupos assessores a iniciativas populares e sindicais, em muitos casos contando com financiamento internacional, mas também com uma forte presença de recursos públicos, configurando-se em uma rica interlocução no que diz respeito a experiências nacionais e no âmbito da América Latina. 


\section{EDUCAÇÃO DE JOVENS E ADULTOS (1959/...) OU “A PRESENÇA MAJORITÁRIA DAS AÇÕES GOVERNAMENTAIS NA ESCOLARIZAÇÃO DE JOVENS E ADULTOS"}

O DVD sobre educação de jovens e adultos representa o maior conjunto documental do thesaurus. São 578 documentos reunidos a partir de onze experiências de campanhas, movimentos e programas quase exclusivamente mantidos e executados por órgãos públicos, inclusive secretarias de educação e universidades federais. Dada a riqueza de informações sobre essas experiências, indicaremos, em sequência cronológica, apenas sua periodicidade e localização e convidamos os leitores à leitura aprofundada do material disponibilizado no DVD.

- Sistema Rádio Educativo da Paraíba (SIREPA), 1959 a 1969: ligado ao Sistema Rádio Educativo Nacional (SIRENA) do Ministério da Educação e Saúde Pública.

- Movimento de Ação Básica Cristã (Cruzada ABC),1962 a 1969: criado no Recife por um grupo de professores do Colégio Evangélico Agnes Erskine, tendo como foco ações de educação de adultos. Financiada pela Aliança para o Progresso e pelo governo federal, após a suspensão pelo regime militar das atividades dos movimentos populares de cultura e educação. Sua base principal foi o estado da Paraíba, estendendo-se a vários estados no Nordeste, chegando ao antigo estado do Rio de Janeiro, em contraposição ao Sistema de Alfabetização Paulo Freire e ao sindicalismo rural.

- Projeto João de Barro (1967 a 1974): iniciativa do Governo José Sarney no estado do Maranhão, que pretendia garantir alfabetização e ensino primário à população rural daquele estado.

- Alfabetização Funcional (1968 a 1970): indica um conjunto de experiências com assessoria da Organização das Nações Unidas para a Educação, a Ciência e a Cultura (UNESCO), implementado na região do agreste pela Associação Nordestina de Crédito e Assistência Rural de Pernambuco (ANCARPE) e em projetos de assentamentos da reforma agrária do Instituto Nacional de Colonização e Reforma Agrária (INCRA), no Nordeste e no atual estado de Mato Grosso do Sul.

- Movimento Brasileiro de Alfabetização (MOBRAL): criado por lei em 1967, passou a atuar efetivamente com o Programa de Alfabetização Funcional (PAF) e o Programa de Educação Integrada (PEI) em todo o país, em convênio com os governos locais a partir de 1970, até sua extinção, em 1986. Contava também com programa de atividades culturais, denominado Programa Diversificado de Ação Comunitária (PRODAC), que a partir da década de 1980 vai ser responsável por várias ações e produção de material diversificado. O MOBRAL foi substituído pela Fundação Educar (1986 a 1990), com o objetivo de coordenar ações de educação básica de jovens e adultos, em regime de descentralização. Sua experiência mais significativa ocorreu na Baixada Fluminense, em estreita colaboração com os fortes movimentos sociais da área. 
- Ensino supletivo (1971 a 1980): amplo programa de educação de adultos, oficializado pela lei n. 5.692/1971, que passa a ser ofertado por cursos e exames, sob execução prioritária dos estados da federação. Os registros no DVD mostram estudos sobre os impactos dessa reforma na educação de adultos nos sistemas públicos e também seus desdobramentos na iniciativa privada, bem como as relações que se estabeleceram entre as ofertas de ensino supletivo na função suplência, as experiências do MOBRAL, como atuações paralelas ao sistema regular de ensino de $1^{\circ}$ e $2^{\circ}$ graus.

- Programa de Educação Juvenil (PEJ): denominado posteriormente Programa de Educação de Jovens e Adultos (PEJA), foi criado no ano de 1985 pelo governo do estado do Rio de Janeiro e se mantém nos dias atuais como alternativa de ensino fundamental para jovens e adultos.

- Movimento de Alfabetização de Jovens e Adultos (MOVA): criado a partir de 1989, quando Paulo Freire foi secretário de educação da cidade de São Paulo; vai estender-se a várias outras cidades do país a partir da década de 1990, passando a atuar na alfabetização e pós-alfabetização, em parcerias entre redes públicas municipais, empresas estatais, organizações não governamentais e movimentos populares.

- Duas experiências de universidades federais são fartamente documentadas: o Projeto Zé Peão, criado em 1990 em uma parceria entre o Sindicato dos Trabalhadores nas Indústrias da Construção e do Mobiliário de João Pessoa (SINTRICOM) e o Centro de Educação e o Programa de Pós-Graduação em Educação da Universidade Federal da Paraíba (UFPB), para a realização de um projeto de alfabetização que se estendeu ao ensino fundamental e busca encaminhar os operários para a conclusão do ensino médio e chegada à educação superior; e o Projeto de Educação Adultos, atendendo funcionários contratados pela Universidade Federal de São Carlos (UFSCar).

- Secretaria de Educação de Jovens e Adultos (SEJA) da cidade de Porto Alegre, no período de 1989 a 2004: foi um importante órgão governamental de coordenação da política de educação de jovens e adultos desse município.

A característica marcante desse conjunto documental é a presença do Estado na realização de ações que, em sua maioria, ultrapassam as iniciativas de alfabetização, propondo-se à continuidade de escolarização de jovens e adultos, como nos programas que integraram a Fundação MOBRAL; as experiências do ensino supletivo; as iniciativas do MOVA e do SEJA dos municípios - após a reabertura política do país - e das universidades federais citadas.

\section{UM THESAURUS A SER EXPLORADO E AMPLIADO}

Como se pode constatar, inúmeras foram e seguem sendo as experiências brasileiras produzidas no âmbito da educação popular e da educação de jovens e 
adultos. A publicação da referida pesquisa documental demonstra a riqueza e a potencialidade criativa e crítica que se colocam à disposição daqueles que querem conhecer a educação brasileira por seus múltiplos olhares. Daqueles que, da geração do "século passado", utilizando-se do melhor em recursos do século XXI, dedicam-se a reunir a história e fazer a história viva da educação popular e da educação de jovens e adultos, ser objeto de pesquisa e aprendizado, teórico e técnico, de um coletivo de experientes e novos pesquisadores. Uma junção entre saber de experiência feito e aprendizagem ao longo da vida, nas faces e biografias de seus organizadores, assistentes de pesquisa, colaboradores e bolsistas, a quem só podemos agradecer da melhor forma possível, que, nesse caso, é acessando esse inestimável acervo para seguir fazendo perguntas tomando-o por base e enriquecendo-o com a sua ampliação, na realização de novas pesquisas.

\section{REFERÊNCIA}

Fávero, O.; Motta, E. (Orgs.). Educą̧ão popular e educação de jovens e adultos. 1. ed. Petrópolis: De Petrus et Alli; Rio de Janeiro: FAPERJ, 2015. DVD-ROM.

\section{SOBRE A AUTORA}

Maria Margarida Machado é doutora em educação pela Pontifícia Universidade Católica de São Paulo (PUC-SP). Professora da Universidade Federal de Goiás (UFG).

E-mail:mmm2404@gmail.com

Recebido em 17 de outubro de 2016 Aprovado em 14 de março de 2017 